\title{
Big data for business modeling: Towards the next generation of performance measurement systems?
}

\author{
Marco Montemari*, Christian Nielsen**
}

The IX Workshop of the Management Control journal provided a great opportunity and platform for constructive discussions on the evolution of management control systems. Coherently with the core theme of the SIDREA national conference, "From crisis to sustainable development: principles and solutions from the perspective of Business Economics", the objective of the Workshop was to promote a debate on the design and adoption of management control systems that are more resilient in times of crisis and thus, more useful in the governing of companies' development process.

It is along these lines that this Special Issue was designed and created. Its point of departure was the call for a substantial innovation in the design, implementation, and use of performance measurement systems (Marchi, 2015), especially in view of the digital revolution that is affecting the way companies operate and compete (Sardi et al., 2020). One of the main implications that arises from the ongoing digital revolution is the tremendous growth of data available to companies, which has led to the phenomenon known as big data, a term that describes a large volume of data, both structured and unstructured, that comes from different sources and grows at ever-increasing rates (Gemmo and Isari, 2018). Big data cannot be analyzed through traditional applications and methodologies, but it requires ad hoc software, called big data analytics, in order to be converted into useful information that can be used to support the managerial decision making process (Petrosino et al., 2018).

As stated by Marchi (2003), data has no value by itself but rather, the value is created when it is processed, organized, presented in a given context, and connected to other relevant data in order to obtain information that can be interpreted and used proactively and intentionally by decision makers.

* Università Politecnica delle Marche, Department of Management, E-mail: m.montemari@staff.univpm.it.

** Aalborg University Business School, E-mail: chn@business.aau.dk.

Management Control (ISSN 2239-0391, ISSNe 2239-4397), 2021, 1 Special Issue

Doi: 10.3280/MACO2021-001-S1001 
It has been acknowledged that the ability to manage big data can play a relevant role in creating value and gaining competitive advantage (McAfee and Brynjolfsson, 2012), and scholars have highlighted the need to design and implement performance measurement systems that integrate big data analytics in order to maximize the value extracted from data (Cupertino et al., 2018; Visani, 2017). However, how big data analytics can enhance a key aspect of performance measurement systems, i.e., their strategic dimension (Sardi et al., 2020) is a stream of research that requires, and deserves, additional attention (Ferraris et al., 2018).

It is exactly at this strategic level that the business model concept can play a crucial role in fostering the integration of big data analytics within performance measurement systems. Although there is still no generally accepted definition of what a business model is (Nielsen et al., 2018), there is gradual agreement on one that describes the business model as the framework through which companies execute their strategy (McGrath, 2010). As a matter of fact, the business model concept makes it possible to conceive a company as a set of interrelated choices regarding its main strategic elements (Morris et al., 2005), including the value proposition; the key activities, resources, and partners needed to develop the value proposition; the target customers and the channels and relationships required to reach them; the cost structure incurred and the revenue streams generated (Osterwalder and Pigneur, 2010).

Among the factors that can lead to the adoption of successful business models, there are also digitalization and big data (Marshall et al., 2015): business models can, in fact, be designed and innovated around a process of collecting, organizing, and analyzing internal and external data, with the goal of increasing the probability of identifying an unmet consumer need, improving product assortment, product recommendations, and promotional efforts (Sorescu, 2017). In other words, big data can offer insights and recommendations on how to update and reshape the business model to effectively respond to changes in market conditions (Loebbecke and Picot, 2015). The stream of research on big data analytics and business models is developing so fast that a term has been coined to identify data-driven business models, described as business models that rely on data as a key resource (Hartmann et al., 2016). A recent literature review by Fruhwirth et al. (2020) on data-driven business models has revealed that existing research tends to focus on tools and methods that support the ideation and design of this type of business model, while little attention has been paid to the tools and methods that support the decision making process in datadriven business models; examples include analysis of costs and benefits of 
data, measurement of created customer value and financial success, and the identification of influencing factors for decisions on revenue models. All of these aspects, especially the latter, that can be addressed through the "technology", i.e., tools and approaches, of performance measurement systems which can enable a better management of the business models.

Thus, there are some potentially relevant contact points between the research stream on big data analytics and performance measurement and that of big data analytics and business models. On the one hand, the business model concept can be a suitable framework in which big data analytics can be integrated into performance measurement systems, thus enabling the strategic use of big data to take decisions on the key logics of a company's value creation, delivery, and capture. On the other hand, performance measurement systems can provide data-driven business models with the processes and the logics needed to not only set goals and develop performance measures, but also to analyze, report, and act on performance data so that decision makers can maximize the value extracted from data.

Therefore, we believe that promising avenues of research lie at the intersections of big data analytics, performance measurement systems, and business models. For example, it could be interesting to investigate how big data analytics can be used to set objectives in different areas of the business model. Another research opportunity relates to exploring how new performance measures can be identified or existing performance measures can be refined, through the insights and the recommendations provided by big data analytics, and how these analytics-based measures can be used to innovate the different aspects of the business model, e.g. the revenue model or the pricing mechanism. A further promising research path might investigate how reporting processes and tools can be reshaped to include insights and recommendations from big data analytics in order to enable a more effective management and control of data-driven business models.

Pushing into these unexplored directions could potentially lead to the next generation of performance measurement systems that are able to convert big data into big impacts by supporting the design and innovation of business models that, in this case, would be truly and fully data-driven.

This Special Issue includes a selection of the papers that aim to address different dimensions of big data analytics, performance measurement and business models, and, in some cases, to investigate aspects that lie at the intersections of these research areas.

Trequattrini, Lombardi, Schimperna, and Manfredi propose a systematic literature review on smart technology applications in the management and strategic control of companies. They highlight four main topic clusters: I) 
business intelligence, competitive intelligence, information analysis, information management; II) artificial intelligence, decision support system, strategic planning, supply chain management; III) business analytics, decision-making, management control systems; IV) big data, information systems, information use. Their findings underscore a strong connection between these smart technologies and the decision-making, planning, and control processes performed by companies. Hence, the scholars pose key questions and identify new research directions that lie at the intersection between smart technologies and management/strategic control systems.

Dicuonzo, Donofrio, Fusco, and Dell'Atti explore how big data and artificial intelligence may support healthcare organizations in promoting sustainable healthcare systems. Through a single case study of the Regional Social Health Agency of Veneto, the authors document that the implementation of artificial intelligence and the use of big data make it possible to perform real time planning and programming that improves economic sustainability (in terms of reducing time and costs), environmental sustainability (in terms of reducing the use of natural resources), and social sustainability (in terms of accessibility to care, regardless of socio-cultural differences).

Through a deductive methodology based on the literature analysis, Cappelli and Cavallini provide a conceptual architecture that proves useful to clarify the possible applications of big data analysis in the shipbuilding sector. With a focus on the pre-production phase of the value chain, the authors identify two main tasks (demand forecasting and sales support) where big data analysis can play a relevant role in improving performance. For these tasks, specific methods and algorithms are provided and summarized to show how they can make processes and operations more cost-effective and help companies to be more competitive.

Vola, Gelmini, and Songini investigate different types of information regarding natural capital and its positioning within the integrated reports of a sample of South African companies. Their evidence shows that, on average, disclosure generally covers historical rather than prospective data, adopts more qualitative than quantitative tones, and is more positive than negative. Moreover, only $50 \%$ of the information gathered is reported in the Business Model \& Value Creation Section. Given these findings, the authors argue that natural capital risks being disconnected from practices effectively carried out by companies; moreover, justifications regarding the environment rather than actions arise, paving the way for use of impression management tools. 
Di Tullio, La Torre, Valentinetti, and Rea start from the consideration that little is known about how business model information is entered and used in companies' accounting information systems. Thus, through a content analysis of the corporate reports and websites of 86 global firms, the authors statistically test coercive, mimetic, and normative forces influencing the institutionalization of business model information and the change of accounting information systems. Their findings show that firms adjusted their accounting information systems to communicate business model information, thereby making it possible to replace their traditional performance measurement systems with new business model-based frameworks able to reflect contemporary conceptions of value creation, delivery, and capture.

Beretta, Demartini, and Trucco - in their study on perceived managerial discretion in the healthcare sector - ground their methodological approach on the performance management literature. Perceived managerial discretion, defined as the actual influence that managers perceive themselves to have regarding the firm's decision-making process, was measured through the answers given by 97 Italian healthcare managers in a survey on the role of performance management systems in supporting their managerial activity. The results from a principal component analysis indicate that perceived managerial discretion can be measured by two items (decision making and flexibility) in three performance management mechanisms (non-financial performance measurement system, budgeting, and performance appraisal system).

Macchia presents a retrospective longitudinal case study of management accounting change in a Co-operative firm in order to enrich the understanding of factors and conditions that make the change happen and develop. The case analysis shows that the search for managerial efficiency, the need to legitimize the company in its external environment, as well as the individuals' behavioral aptitudes, are all factors potentially able to explain why the company decided to invest in a management accounting change. Despite different forms of resistance, more or less explicit, which hindered the project during the implementation process, the management control system played a significant role in creating and fostering trust in innovation and change.

In closing, we hope that the reader will find the papers included here of value. We would like to thank all authors for their contributions and the reviewers for their time and effort spent reviewing the manuscripts. Our special thanks go to the Editor-in-Chief, Professor Luciano Marchi, for his support during the production of this Special Issue, and to Alessandra Goti, for her excellent, conscientious editorial assistance. 


\section{References}

Cupertino S., Vitale G., Riccaboni A. (2018), L'impatto dei Big Data sulle attività di pianificazione \& controllo aziendali: Un caso di studio di una PMI agricola Italiana, Management Control, 3, pp. 59-86. Doi: 10.3280/MACO2018-003004.

Ferraris A., Mazzoleni A., Devalle A., Couturier J. (2018), Big data analytics capabilities and knowledge management: Impact on firm performance, Management Decision, 57, 8, pp. 1923-1936.

Fruhwirth M., Ropposch C., Pammer-Schindler V. (2020), Supporting data-driven business model innovations: A structured literature review on tools and methods, Journal of Business Models, 8, 1, pp. 7-25.

Gemmo e Isari (2018), Il ruolo manageriale nell'era digitale. Cambiamenti in atto nelle organizzazioni e scenari futuri del ruolo manageriale, Torino, Giappichelli Editore.

Hartmann P.M., Zaki M., Feldmann N., Neely A. (2016), Capturing value from big data - A taxonomy of data-driven business models used by start-up firms, International Journal of Operations \& Production Management, 36, 10, pp. 1382-1406.

Loebbecke C., Picot A. (2015), Reflections on societal and business model transformation arising from digitization and big data analytics: A research agenda, The Journal of Strategic Information Systems, 24, 3, pp. 149-157.

Marchi L. (2003), I sistemi informativi aziendali, II edition, Giuffrè Editore, Milano.

Marchi L. (2015), Nuove prospettive di ricerca sulle tematiche di Management Control, Management Control, 3, pp. 5-8. Doi: 10.3280/MACO2015-003001.

Marshall A., Mueck S., Shockley R. (2015), How leading organizations use big data and analytics to innovate, Strategy \& Leadership, 43, pp. 32-39.

McAfee A., Brynjolfsson E. (2012), Big data: The management revolution, Harvard Business Review, 90, 10, pp. 60-68.

McGrath R.G. (2010), Business models: A discovery driven approach, Long Range Planning, 43, 2-3, pp. 247-261.

Morris M., Schindehutte M., Allen J. (2005), The entrepreneur's business model: Toward a unified perspective, Journal of Business Research, 58, 6, pp. 726-735.

Nielsen C., Lund M., Montemari M., Paolone F., Massaro M., Dumay J. (2019), Business models. A research overview, New York, NY, Routledge.

Osterwalder A., Pigneur Y. (2010), Business model generation: A handbook for visionaries, game changers and challengers, Hoboken, NJ, John Wiley and Sons.

Petrosino A., Mancini D., Garzella S., Lamboglia R. (2018), La Business Intelligence e la Business Analytics nell'era dei Big Data: una analisi della letteratura, Management Control, 3, pp. 31-58. Doi: 10.3280/MACO2018-003003.

Sardi A., Sorano E., Cantino V., Garengo P. (2020), Big data and performance measurement research: Trends, evolution and future opportunities, Measuring Business Excellence, ahead of print.

Sorescu A. (2017), Data-driven business model innovation, Journal of Product Innovation Management, 34, 5, pp. 691-696.

Visani F. (2017), Applying business analytics for performance measurement and management. The case study of a software company, Management Control, 2, pp. 89123. Doi: 10.3280/MACO2017-002006. 